\title{
Amphibian community structure along elevation gradients in eastern Nepal Himalaya
}

\author{
Janak R. Khatiwada ${ }^{1,2}$, Tian Zhao ${ }^{1 *}$,, Youhua Chen ${ }^{1}$, Bin Wang ${ }^{1}$, Feng Xie ${ }^{1}$, David C. Cannatella ${ }^{3}$ \\ and Jianping Jiang ${ }^{1}$
}

\begin{abstract}
Background: Species richness and composition pattern of amphibians along elevation gradients in eastern Nepal Himalaya are rarely investigated. This is a first ever study in the Himalayan elevation gradient, the world's highest mountain range and are highly sensitive to the effects of recent global changes. The aim of the present study was to assess amphibian community structure along elevation gradients and identify the potential drivers that regulate community structures. Amphibian assemblages were sampled within 3 months in both 2014 and 2015 (from May to July) using nocturnal time constrained and acoustic aids visual encounter surveys. In total, 79 transects between 78 and $4200 \mathrm{~m}$ asl were sampled within 2 years field work. A combination of polynomial regression, generalized linear models, hierarchical partitioning and canonical correspondence analysis were used to determine the effects of elevation and environmental variables on species richness, abundance, and composition of amphibian communities.
\end{abstract}

Results: Species richness and abundance declined linearly with increasing elevation, which did not support the MidDomain Model. Among all the environmental variables, elevation, surface area and humidity were the best predictors of species richness, abundance and composition of amphibians. The majority of amphibian species had narrow elevation ranges. There was no significant correlation between species range size and elevation gradients. However, body size significantly increased along elevation gradients, indicating that Bergmann's rule is valid for amphibians in eastern Nepal Himalaya.

Conclusions: This study indicates that eastern Nepal Himalaya is a hotspot in amphibian diversity, and it should be served as a baseline for management and conservation activities.

Keywords: Amphibians, Community structure, Environmental correlation, Elevational diversity gradient, Ecology of the Himalayas

\section{Background}

Understanding how community patterns (e.g., species richness, abundance, distribution range size, and body size variation) change along elevation gradients have been a central topic in modern ecology, biogeography, and conservation [1]. As one metric of community

\footnotetext{
*Correspondence: zhaotian@cib.ac.cn

${ }^{1}$ CAS Key Laboratory of Mountain Ecological Restoration and Bioresource Utilization \& Ecological Restoration and Biodiversity Conservation Key Laboratory of Sichuan Province, Chengdu Institute of Biology, Chinese Academy of Sciences, Chengdu 610041, China

Full list of author information is available at the end of the article
}

structure, species richness is expected to decrease with increasing elevation [2], which can be attributed to the difference of species distribution and composition. Many previous studies have demonstrated the determination of biotic and abiotic factors on species richness and distribution along elevational gradients in local communities. Specifically, climate factors (e.g., temperature and rainfall) can be considered as the first filters acting on species richness and distribution [3, 4]. Then, larger land surface area is expected to support more individuals and species under similar climatic conditions $[5,6]$. Biological interactions (e.g., competition, predation, and productivity) 
can influence the occurrence of species and, to a greater extent, species richness $[7,8]$. In amphibians habitat, the first environmental filters acting on species richness is heterogeneity [9-11]. This is because the heterogeneity of habitats can provide quantitative amphibian species different vegetation types, which associated with food resources, space, and microhabitat types [10-12]. However, habitats heterogeneity can be disturbed by human activities through pollution, degradation, and land use change (e.g., deforestation), causing the cascading effects on amphibian communities such as taxonomic homogenization and species richness decline [11-13].

Species distribution range size is another important component of community structure. It is considered to be a major factor that is highly correlated with extinction risk in organisms, and is also critical to study biotic responses to environmental factors [14]. Species with small distribution range will be more at risk as their entire range can be more easy to be affected by threatening factors [15]. More importantly, these species usually have small population, which may induce inbreeding and demographic stochasticity, and thus further enhance extinction risk in the long run [16]. Various rules have been proposed to explain the response of distribution range of species along elevation gradients [17]. Rapoport's rule, for instance, states that species adapted to higher elevations should have a larger distribution range because of climatic tolerance [18]. Indeed, species distribution range is the fundamental unit of species richness gradients [19]. This is because species distribution range is related to elevation boundaries, and species with large distribution range must have their distribution midpoints closed to the center of the domain (i.e., elevation) [20]. As a greater number of organisms mid-range appear at the mid-elevation (e.g., plants [21]; mammals [22]; birds [3]; and fish [23], increasing overlap of species distribution range toward the centers result in the highest species richness occurred at the middle elevations [20]) (but in the convergence area, species richness increases [24]). Therefore, a hump shape relationship between species richness and elevation gradients can be detected (i.e., mid-domain effect [25]).

In addition, body size structure is a key concept with its ecological role comparing to other facets of community structures. This is because it provides information about animals life history [26], predator-prey interactions [27], and extinction risk [14] to ecologists and conservationists. To correlate the body size and environmental gradient, it is stated that organisms tend to be larger in cooler climates $[28,29]$ and afterward this concept has been named as Bergmann's rule. This rule has been proved to be true for some endothermic animals (e.g., mammals and birds $[3,30])$, but not always true for ectothermic animals (e.g., fish [31], reptiles [32], and amphibians [33]) which could be advantageous in cold areas to gain heat faster according to heat balance hypothesis [34]. Therefore, the test of Bergmann's rule for amphibians in Himalayan region will help ecologists to better explain body size patterns, and to conduct amphibians conservation in this area.

Empirical studies have demonstrated the responses of different taxa along elevation gradients on mountains (see Additional file 1: Table S1). However, there is still a gap in our understanding of the elevation gradients in the amphibian community structure in eastern Nepal Himalaya. In addition, given both elevation and other environmental factors (e.g., habitat type, humidity, and canopy cover) play important roles in structuring amphibian communities [35], we argue that elevation and community data cannot be accurately dealt with using the unidimensional approach. It is better to incorporate elevation and other environmental factors to document and analyze these data, especially species richness and composition. Therefore, the objectives of the present study were to (1) explore the responses of amphibian species richness, abundance, distribution range size, and body size to elevation gradients, and to (2) quantify the environmental determinants of species richness, abundance, and composition in eastern Nepal Himalaya. Based on previous studies (e.g., Hu et al. [36] and Fu et al. [37]), we predict that amphibian species richness, abundance, and distribution range size may display hump-shape curves along the elevation gradients, while body size may increase linearly along the elevation gradients. We also predict that humidity, air temperature, canopy cover of vegetation, and land surface area could be more important to determine amphibian community structures in eastern Nepal Himalaya.

\section{Materials and methods Study area}

The present study was conducted in the catchment of the Koshi basin in Eastern Himalaya in Nepal $\left(27.33805^{\circ}\right.$ to $26.31893^{\circ} \mathrm{N}$ and $86.5994^{\circ}$ to $88.2133^{\circ} \mathrm{E}$ ), where the elevation ranged from 78 to $3430 \mathrm{~m}$ above sea level (m asl; Fig. 1) within a short geographic distance $(135 \mathrm{~km})$. This region is characterized by rugged terrain and large climatic gradients, with the mean annual temperature is $15{ }^{\circ} \mathrm{C}( \pm 6 \mathrm{SD})$, and the annual precipitation is about $1800 \mathrm{~mm}$ (concentrated during monsoon season-May to October; [38]). Specifically, the study area can be divided into five distinct climatic zones [39, 40], those that correspond to specific vegetation zones. The lowland area $(<1000 \mathrm{~m}$; the tropical and sub-tropical zone) is dominated by Shorea robusta, Adina cordifolia, Dalbergia sissoo and Terminalia spp. The warm temperate zone 


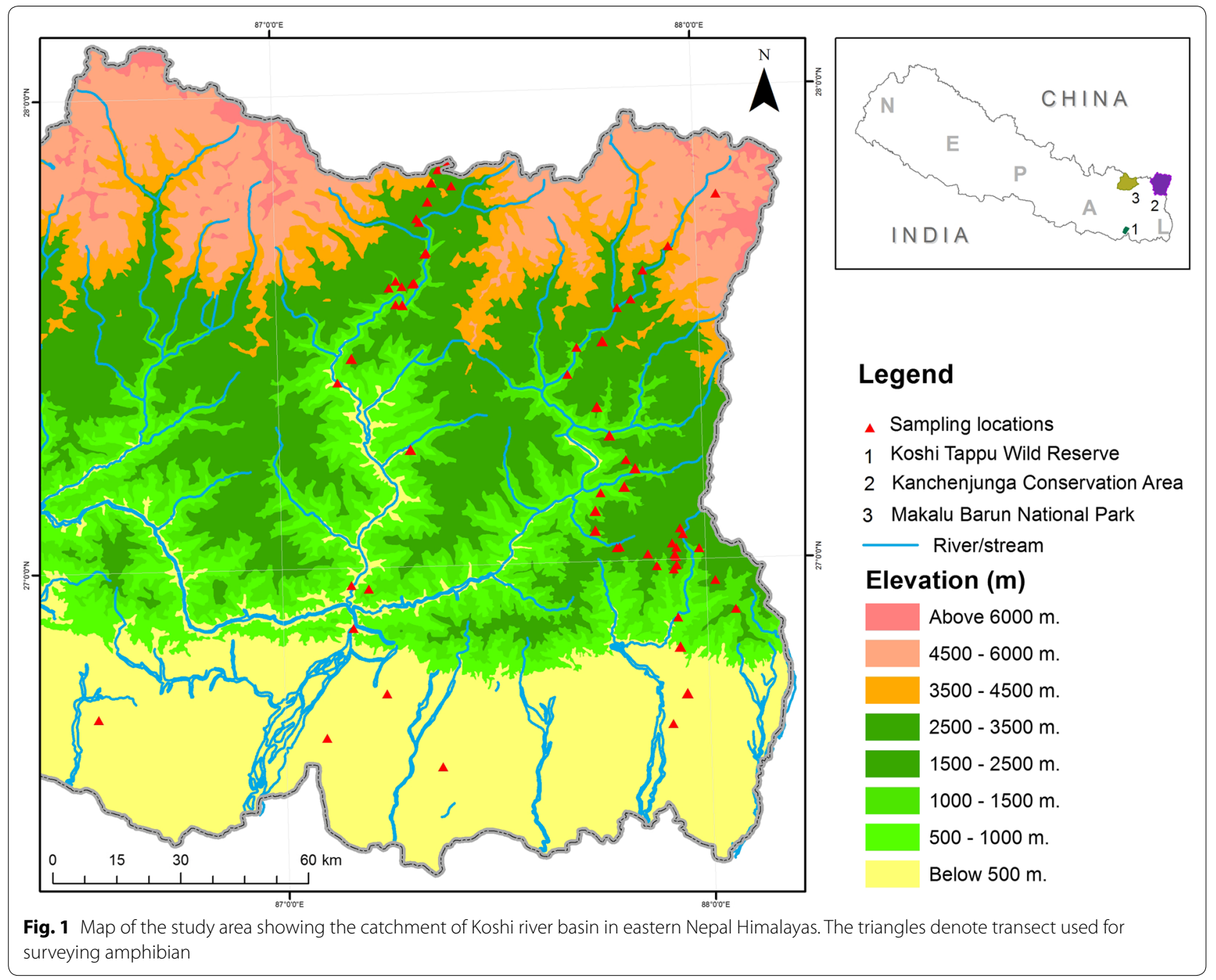

(1000 to $2000 \mathrm{~m}$ ) is composed of evergreen broad leaf forest, which is dominated by Schima wallichii, Castanopsis indica and Pinus roxburghii. Evergreen broadleaf forest and deciduous broadleaf mixed forest dominate the cool temperate zone (2000-3000 m), with the abundant species are Quercus and Rhododendron species. In the sub-alpine zone (3000 to $4000 \mathrm{~m}$ ), Betula utilis occupies the evergreen conifer forest. Above $4000 \mathrm{~m}$ can be considered as the alpine zone, with the vegetation dominated by Abies spectabilis, Sorbus microphylla, Rhododendron spp., Salix spp. and alpine meadows with different species of grasses [41].

\section{Amphibian sampling}

Amphibian communities were sampled within 3 months in both 2014 and 2015 (from May to July, coincide with the rainy season) using nocturnal time constrained visual encounter and acoustic aids surveys, which is an effective method to cover entire amphibian community including terrestrial, arboreal, aquatic as well as fossorial and even well-camouflaged species [42-44]. This method involved four people systematically walking at a slow pace, intensively searching for amphibian species by turning over the stones, logs, leaf litters, tress branches, shrub and bushes along the transects $(100 \mathrm{~m} \times 4 \mathrm{~m})$ [44]. The searches were conducted using $220 \mathrm{~lm}$ torches and each transect was searched for $1 \mathrm{~h}$ between 19:00 $\mathrm{h}$ and 23:00 $\mathrm{h}$ after the sun set every night, with one to three transects being sampled per night [44]. In total, 79 sites located in different elevations between 78 and $3430 \mathrm{~m}$ (Fig. 1) were sampled within 2 years field work, with each site was sampled only once in the sampling period. As amphibians are usually found near water bodies, all transects were placed nearby water sources as possible. To reduce spatial autocorrelation, all transects were separated from each other by a deep mountain gorge, stream or other prominent landmarks. 
All individuals encountered were captured and stored in 15-1 plastic buckets with small holes on the lid. Individuals that could not be captured were also counted. To ensure a comprehensive species list for each survey site, advertisement calls of breeding males were also recorded with a Marantz PMD670 recorder using a Sennheiser ME 66 shotgun microphone (16-bit resolution, sampling rate $44.1 \mathrm{kHz})$. Most of the species were detected by the loud and sharp calls of males [45]. All captured individuals were taken to a nearby dry place where they were photographed, identified to species and sex based on books such as Schleich and Kästle [46] and Shah and Tiwari [47], measured for body size (i.e., the maximum snout to vent length; SVL) following Olalla-Tárraga and Rodríguez [34] using a digital caliper to the nearest $0.5 \mathrm{~mm}$, and released back into their original habitats. In order to prevent the transmission of diseases between individuals, new latex gloves were used for each individual during the measurement. Individuals that were difficult to identify based on morphological traits were euthanized in a chlorobutanol solution, fixed in natural formalin for $24 \mathrm{~h}$ and preserved in $75 \%$ ethanol. Vouchers were deposited at the Natural History Museum, Tribhuvan University, Kathmandu, Nepal. The species nomenclature herein follows that of Frost [48]. All amphibians handling and processing were in accordance with the guidelines of the Department of National Park and Wildlife Conservation, Nepal.

\section{Environmental variables}

Environmental variables (i.e., elevation, humidity, air temperature, water temperature, canopy cover of vegetation, litter cover, land surface area, and above-ground net primary productivity) were collected based on their potential importance in shaping amphibian species composition in the field [35, 42]. These variables were obtained as follows: elevation was recorded to the nearest meter by using an altimeter (Sun Altimeter). Air and water temperature were measured at five different locations at each transect using mercury thermometer. Relative humidity was measured in percentages (five replicates within $20 \mathrm{~m}$, and values were averaged for each transect) by using a digital humidity meter (Peakmeter MS6508). Canopy cover (\%) of the vegetation was measured using a spherical densitometer in five locations per transect, with each location was measured toward four directions $(\mathrm{N}, \mathrm{S}, \mathrm{E}, \mathrm{W})$, and the averaged data was then used in statistical analyses [49]. Litter cover (\%) was visually estimated in percentage at each location. Land surface area of each elevation band was calculated from a digital altitude model according to Zhang et al. [50]. Above-ground net primary productivity of each survey site can be represented as Normalized Difference
Vegetation Index (NDVI), which was extracted from web page (http://earthexplorer.usgs.gov/) for 3 years (2014-2016) using ERDAS IMAGINE 9.2 (ERDAS, Norcross, GA, USA). NDVI were then averaged for the final analyses.

\section{Statistical analyses}

Species richness was represented by the number of species, and abundance by the total number of individuals of each species. Species accumulation curves were computed using EcoSim7.0 [51] and used to test whether the sampling effort was adequate $[22,52]$.

We first used polynomial regressions with first order to explore the responses of species richness and abundance to elevations. The MDE null model was then computed using RangeModel 5.0 [53]. This program generates a null model for the distribution of species richness along the elevation gradients using range size and mid-points. We used 10,000 simulations without replacement to generate an interpolated richness with $95 \%$ prediction curves. The relationship between interpolated richness and elevation gradients was also explored using a linear regression. Species recorded only at one elevation point were adjusted by adding $50 \mathrm{~m}$ to lower elevation limit or $150 \mathrm{~m}$ to upper limit as described by Cardelús et al. [54] and Wu et al. [55]. Finally, Pearson correlation was used to examine the relationship between observed species richness and interpolated richness.

The range size of each species was estimated by calculating the difference between the lowest and highest elevation of its presence [22]. Polynomial regressions (first and order) were used to assess whether amphibian species' range size follow the prediction of Rapoport's rule $[18,56]$. Linear regression was used to determine the relationship between body size (SVL) and elevations (i.e., the test for Bergmann's rule). Only adults were included in the analyses.

Prior to multivariate analyses, variance inflation factor (VIF) was calculated to check the multicollinearity between environmental variables. High multicollinearity was detected between elevation, water temperature and air temperature [57] (Additional file 1: Table S2). Air temperature and water temperature are significantly correlated with elevation $(\mathrm{r}=-0.947, P<0.001 ; \mathrm{r}=-0.922$, $P<0.001$ ), both water temperature and air temperature were excluded in the multivariate regression analyses to reduce the multicollinearity [57]. Generalized linear models (GLMs) with Gaussian distribution error was used to examine the relationships between species richness/abundance and explanatory variables (elevation, humidity, canopy cover, leaf-litter cover and NDVI). The best GLM model was selected based on the lowest AIC value [58]. When required, environmental variables were 
log transformed prior to meet the assumptions of GLM models. These analyses were carried out using the $R$ package MASS [59]. In addition, we also used hierarchical partitioning $[60,61]$ to compare the relative contribution of different environmental variables to the variation of amphibian species richness and abundance. Hierarchical partitioning (hier.part function in the $\mathrm{R}$ package) calculates goodness-of-fit measures according to all possible combinations of explanatory variables [62], and identifies the independent contribution of each explanatory variable [61]. The effects of environmental variables on species composition was tested using a canonical correspondence analysis (CCA) in Canoco 4.5 software [63]. A forward selection procedure with a Monte Carlo permutation test with 999 iterations was applied.

\section{Results}

A total of 1286 individual belonging to 29 species from two orders (one Urodela and 28 Anura) and seven families were recorded in our study (Additional file 2: Table S3). The sample-based rarefaction curve attained an asymptote, indicating that the sampling effort was adequate (Additional file 2: Figure S1). Species richness per transect ranged from 0 to 12 , with a mean of $3.7 \pm 2.9$ SD. The most abundant species were Duttaphrynus melanostictus ( $\mathrm{N}=193 ; 15.1 \%$ of all observed individuals), Euphlyctis cyanophlyctis $(\mathrm{N}=182 ; 14.3 \%)$, Fejervarya sp. $(\mathrm{N}=154 ; 12.1 \%)$, Tylototriton himalayanus $(\mathrm{N}=118$; 9.3\%) and Polypedates maculatus $(\mathrm{N}=104 ; 8.2 \%$, (Additional file 2: Table S3). In contrast, Microhyla taraiensis, Uperodon sp., Kaloula sp. and Sylvirana nigrovittata were rare species, which occupied $<1 \%$ of the total number of captured individuals (Additional file 2: Table S3).

Species richness and abundance along elevation gradients Both species richness and abundance exhibited monotonically declining trends with increasing elevations
$\left(R^{2}=0.45, P=0.001\right.$ and $R^{2}=0.31, P=0.001$, respectively; Fig. 2). Interpolated richness from the MDE null model showed an overall linear declining trend with elevations $\left(R^{2}=0.93, P=0.001\right.$; Additional file 2 : Figure $\mathrm{S} 2)$. Moreover, observed and interpolated species richness were positively correlated with each other $\left(R^{2}=0.45\right.$, $P=0.001, N=79$ ).

\section{Species distribution range size and body size}

About 33\% of the amphibian species portrayed a narrow elevational range profile $(78-500 \mathrm{~m}), 21 \%$ of the species showed wide elevational distribution $(78-1800 \mathrm{~m})$, and no individuals were recorded above $3450 \mathrm{~m}$ (Additional file 2: Figure S3). Seven species were restricted to low-elevation sites, and they were recorded only below $350 \mathrm{~m}$ (Hylarana nigrovittata, Hoplobatrachus crassus, Hoplobatrachus tigerinus, Polypedates taeniatus, Uperodon globulosus, Spherotheca rolandae and Kaloula taprobanica). Polynomial regression revealed that the species range size portrayed a curvilinear relationship $\left(R^{2}=0.38, P<0.001\right)$ with elevation mid-point (average of upper and lower limit) rather than a linear one $\left(R^{2}=0.03\right.$, $P=0.309$ ) (Fig. 3). This indicated that the response of amphibian species range size to elevation gradients cannot be explained by Rapoport's elevation rule in eastern Nepal Himalaya.

Amphibian body sizes have a large variation. Species with smallest body size was Microhyla nilphamarensis $(18.28 \mathrm{~mm} \pm 1.48 \mathrm{SD})$, and species with largest body size was $H$. tigerinus $(83.03 \mathrm{~mm} \pm 20.45 \mathrm{SD})$. Body size of all amphibians (including all the individuals) significantly increased along elevation gradients $\left(R^{2}=0.244, P<0.001\right.$, Fig. 4a). Similar trend can be also detected when individuals were divided based on the sex (i.e., Male: $R^{2}=0.217$, $P<0.001$ and Female: $\left.R^{2}=0.09, P<0.001\right)$. Overall, the results suggested that amphibian species in eastern Nepal Himalaya followed Bergmann's rule. However, at
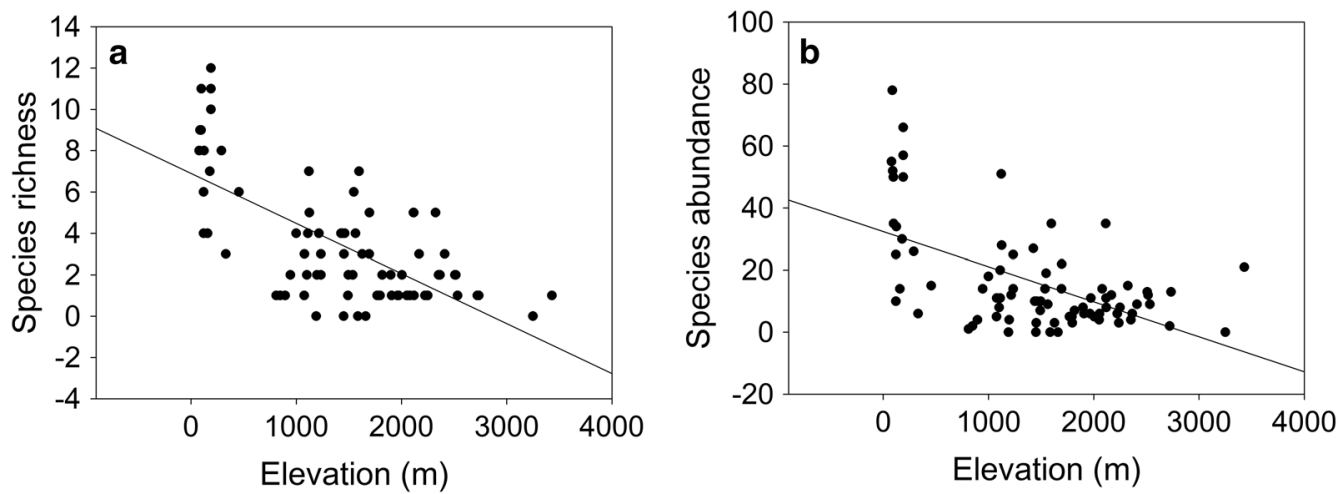

Fig. 2 Variation of $\mathbf{a}$ species richness and $\mathbf{b}$ species abundance along the elevation gradients in eastern Nepal Himalaya 


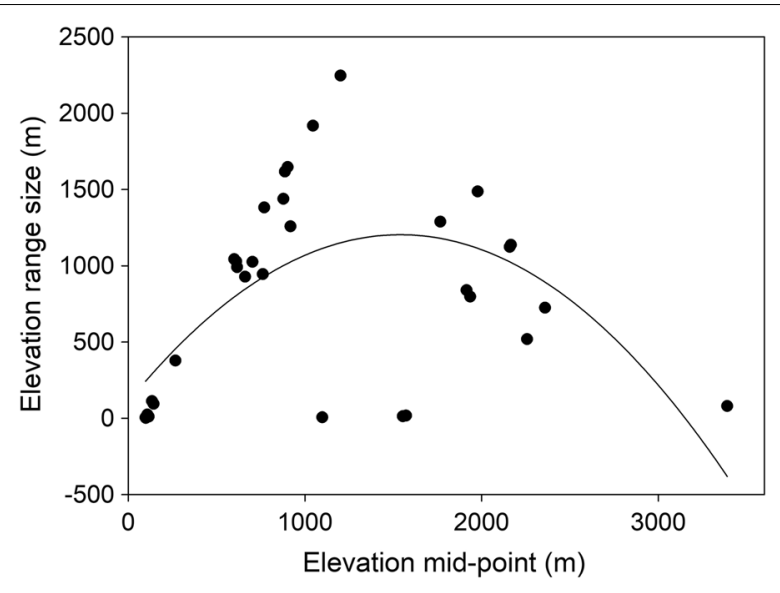

Fig. 3 Relationship between elevation range size and elevation mid-point of each amphibian species in eastern Nepal Himalaya

family level, only four out of seven families (Bufonidae: $R^{2}=0.096, P<0.001$; Dicroglossidae: $R^{2}=0.251, P<0.001$; Megophryidae: $R^{2}=0.158, P=0.01$; and Rhacophoridae: $R^{2}=0.153, P=0.004$, Fig. $4 \mathrm{~b}-\mathrm{e}$ ) showed significant increasing trend whereas Salamandridae $\left(R^{2}=0.160\right.$, $P<0.00$, Fig. 4f) showed declining trend along elevations (Fig. 6). Two families namely Ranidae $\left(R^{2}=0.045\right.$, $P=0.248$, Fig. $4 \mathrm{~g})$ and Microhylidae $\left(R^{2}=0.071\right.$, $P=0.122$, Fig. 4 h) exhibited non-significant trend along elevation gradients.

\section{Effects of environmental variables on species richness, abundance and composition}

Land surface area of elevation band and humidity were included in the best GLM model to explain the variation in both amphibian richness and abundance (Table 1). Specifically, both species richness and abundance had significant positive relationships with land surface area of elevation band $(P<0.001$ and $P=0.001$; respectively). Hierarchical partitioning analyses showed that land surface area of elevation band contributed the most to the variation of species richness and abundance $(50.2 \%$ and 57.6\%; respectively). While the second most important contributor was elevation, which explained $39.5 \%$ variation of species richness and $28.3 \%$ variation of species abundance, respectively (Fig. 5).

The CCA model revealed the significant effects of environmental factors on species composition $(P<0.01)$. The first two axes explained $13.7 \%$ of the variation $(10.3 \%$ and $3.4 \%$ respectively). Elevation, surface area and NDVI had a significant effect on species composition $(P<0.05)$ (Fig. 6). T. himalayanus, A. formosus, P. annandalii, $D$. himalayanus, $N$. liebigii, Scutiger spp. and M. parva were positively associated with elevation and negatively with land surface area of elevation band. In contrast, $K$. taprobanica, S. nigrovittata, $H$. crassus, $H$. tigerinus, $S$. ronaldae, $P$. taeniatus and $D$. stomaicus were positively associated with land surface areas and negatively with elevation. Some amphibian species such as $F$. nepalensis, F. terainesis, F. pierrei and A. marmoratus were positively influenced by NDVI (Fig. 4).

\section{Discussion}

The present study examined amphibian community structure along elevation gradients in eastern Nepal Himalaya. Our results indicated that amphibian community structure (i.e., species richness, abundance, range size, and body size) varied significantly from low to high elevations. This is because of the different amphibian species distribution and composition which can be driven by environmental variables such as elevation, land surface area of elevation band, and NDVI $[9,50]$.

A total of 29 amphibian species were detected in the studied area, which covered more than $50 \%$ of the total amphibian species in Nepal [47], indicating the high amphibian species richness in eastern Nepal Himalaya. We found linear declining relationships between species richness/abundance and elevation gradients (from 12 to 0 , and from 80 to 0 ), indicating that more amphibians prefer low elevation climate and micro-environment conditions. This is a typical pattern reported for the herpetofauna $[64,65]$. In addition, previous study also confirmed the similar declining trend of reptiles richness along elevation gradients in the adjoining Eastern Sikkim Himalaya [66]. This is mainly caused by the decrease in temperature [67], with the lapse rate of temperature is estimated about $0.53{ }^{\circ} \mathrm{C} / 100 \mathrm{~m}$ along elevation gradients in Nepal [68]. As the ectothermic organisms, it is widely recognized that higher temperature and precipitation in low elevation locations can usually support more species and individuals $[3,4]$. And fewer amphibian species are able to survive in cold high elevation regions [69], except salamanders which will increase their species richness along elevations as many salamander species prefer cool and moist climates [70,71]. However, the observation is in contrast with previous studies showing that amphibian species richness can exhibit a hump-shape response to elevation gradients in other mountain regions such as Hengduan Mountains, China [31] and tropical Andes [72]. This is because the mid-domain effect can be affected by sampling effort, geometric constraints on species range boundaries, and geographical scales [21, 25, 50]. In the present study, the sample-based rarefaction curve attained an asymptote, which indicated that sampling effort did not significantly influence the relationship between species richness and elevation gradients. Moreover, our results demonstrated that most of the amphibian species displayed a narrow range size instead 

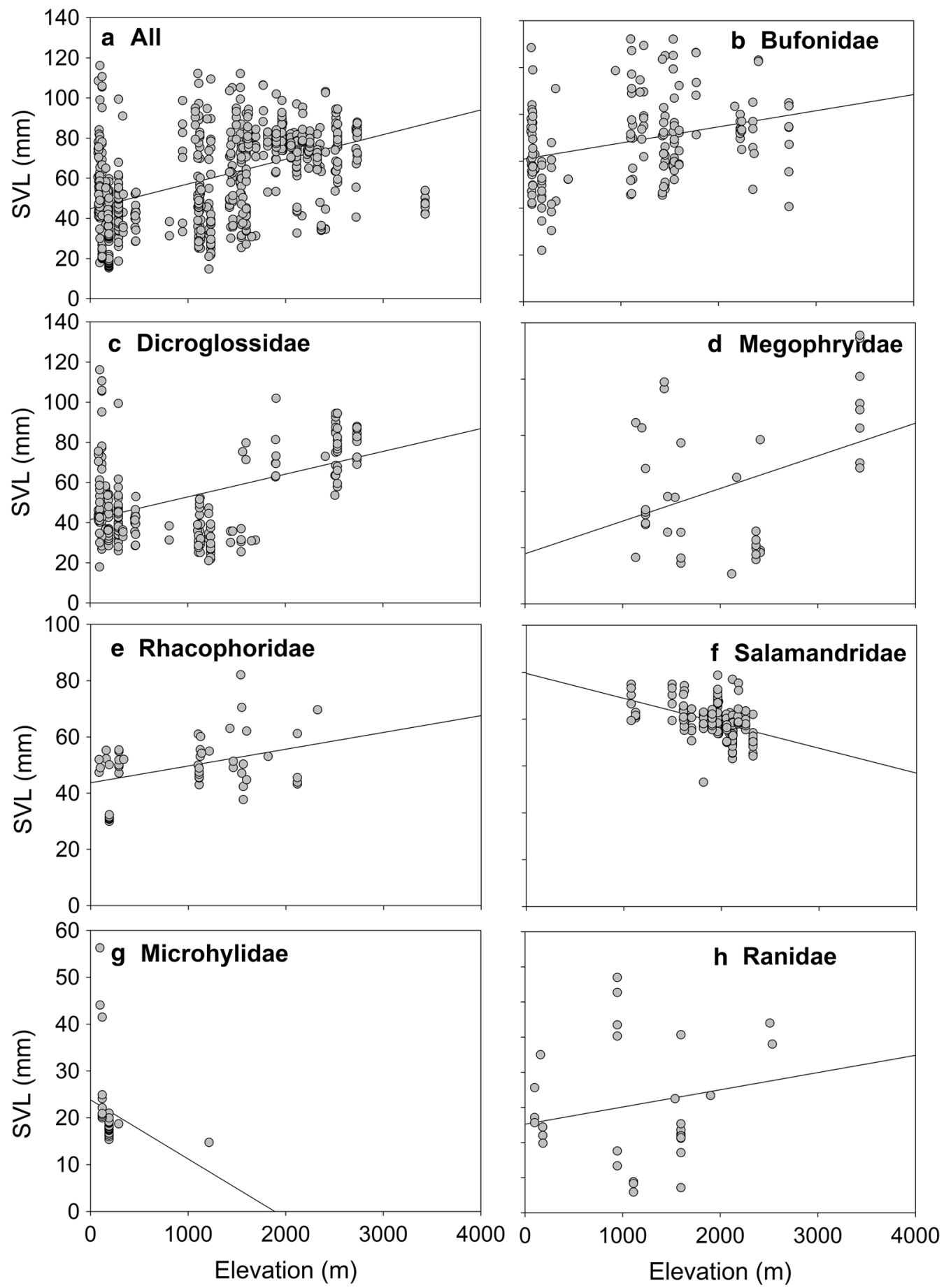

Fig. 4 Relationships between amphibians body size and elevation in eastern Nepal Himalaya. The dots represent individuals 
Table 1 Results of the generalized linear model, using species richness and abundance as the dependent variable and elevation, humidity, canopy cover, litter coverage, NDVI, area (log transformed) as the independent variables

\begin{tabular}{lcccc}
\hline Variable & Estimate & SE & t-value & P-value \\
\hline $\begin{array}{l}\text { Species richness } \\
\quad\end{array}$ & & & & \\
Surface area (log) & 7.120 & 0.758 & 9.390 & $0.000^{* * *}$ \\
Humidity & 0.034 & 0.024 & 1.427 & 0.158 \\
$\begin{array}{l}\text { Species abundance } \\
\quad \text { Surface area (log) }\end{array}$ & 37.565 & 4.772 & 7.871 & $0.000^{* * *}$ \\
Humidity & 0.218 & 0.151 & 1.441 & 0.154 \\
\hline
\end{tabular}

The asterisks denote the significance level $\left({ }^{* * *} P<0.001\right)$

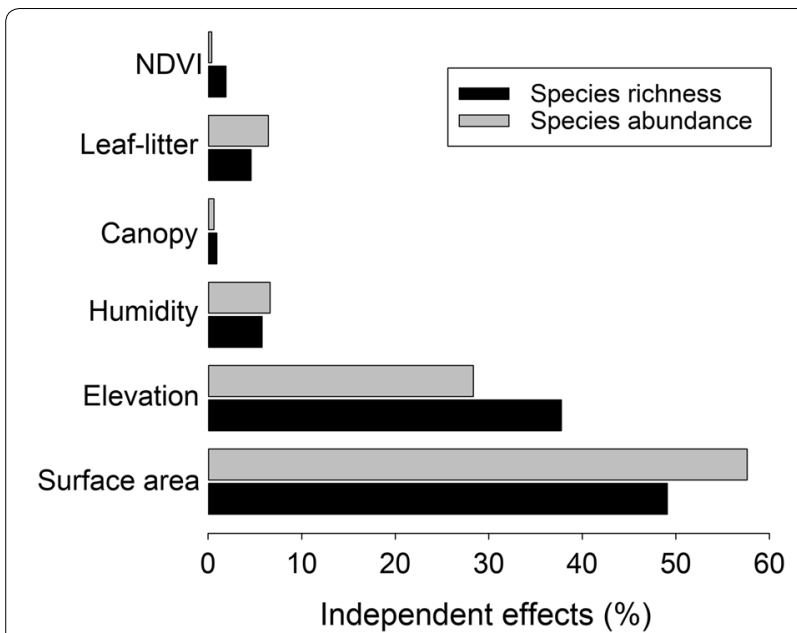

Fig. 5 Results of hierarchical partitioning showing the independent contribution of environmental variables in the variations of amphibian species richness and abundance

of a uniform distribution. This is likely the main reason that amphibian species in eastern Nepal Himalaya does not follow the MDE prediction.

Moreover, the curvilinear relationship between species distribution range and elevation gradients indicated that the Rapaport's rule also cannot used to explain elevation patterns of amphibian community structure in eastern Nepal Himalaya. This is because most species captured in the present study were elevation specialists, with their distribution range were very narrow. For example, $U$. globulosus, Kaloula taprobonica, H. crassus and P. taeniatus were low-elevation restricted species $(<400 \mathrm{~m})$. In contrast, Scutiger sp. was only recorded above $3400 \mathrm{~m}$. Our results supported the claims that Rapoport's rule is a regional, but not a global phenomenon [15].

Interestingly, we found a significant correlation between body size and elevation, confirming the predictions of Bergmann's rule for amphibians in eastern Nepal
Himalaya in overall amphibian data. Indeed, Bergmann's rule widely exists in homeothermic animals such as mammals and birds [73, 74], as these large animals have strong ability to adjust themselves to adapt to the changing environment. However, it is usually not the same case in poikilotherm animals (e.g., Liolaemus lizards; [32], and fresh water fish; [75]). For amphibians, empirical support for the Bergmann's rule is still controversial [76]. Some regional amphibian species followed the Bergmann's rule $[34,36,77]$ whereas others did not $[76,78]$. In the present study, we found the inverse of Bergmann's rule for the family Salamadridae (T. himalayanus), which was consistent with previous findings showing the similar patterns of North-American and Europeans Urodele [34]. Therefore, future studies should focus on the mechanisms that mediate the Bergmann's rule in amphibian species. Further, the cascading effects of Bergmann's rule on ecosystem functioning should also be investigated.

The multivariate analyses (i.e., GLM, hierarchical partitioning and CCA) showed that land surface area of elevation band was the most important variable that affected amphibian species richness, abundance and composition in eastern Nepal Himalaya. These results complement the area-species hypothesis indicating that there are more individuals and species can be found in the elevation band with larger land surface area $[5,6,79])$. It is not surprising that humidity was the second most important variable that can influence amphibian community structure, as it is a critical factor to determine amphibian reproduction and thermoregulation [80]. More importantly, humidity also linked with water availability and is considered as the surrogate of productivity $[81,82]$. And more productive habitats (NDVI) can support more species and individuals $[83,84]$. This shows that the productivity hypothesis is well supported by amphibian species in eastern Nepal Himalaya [83, 84].

\section{Conclusions}

This study indicates that eastern Nepal Himalaya is rich in amphibian diversity, which decreases along the elevation gradients. This is because lower elevation areas are larger, and they can also provide suitable habitats for amphibians (i.e., more humidity and food). Moreover, based on the curvilinear relationship between species range size and elevation gradients, our results support the claims that Rapoport's rule is not suitable for all the taxa globally. Interestingly, our results demonstrate the acceptance of Bergmann's rule of amphibian body size variation in eastern Nepal Himalaya. Overall, our results could provide important baseline information to design effective conservation and management strategies in the future. 


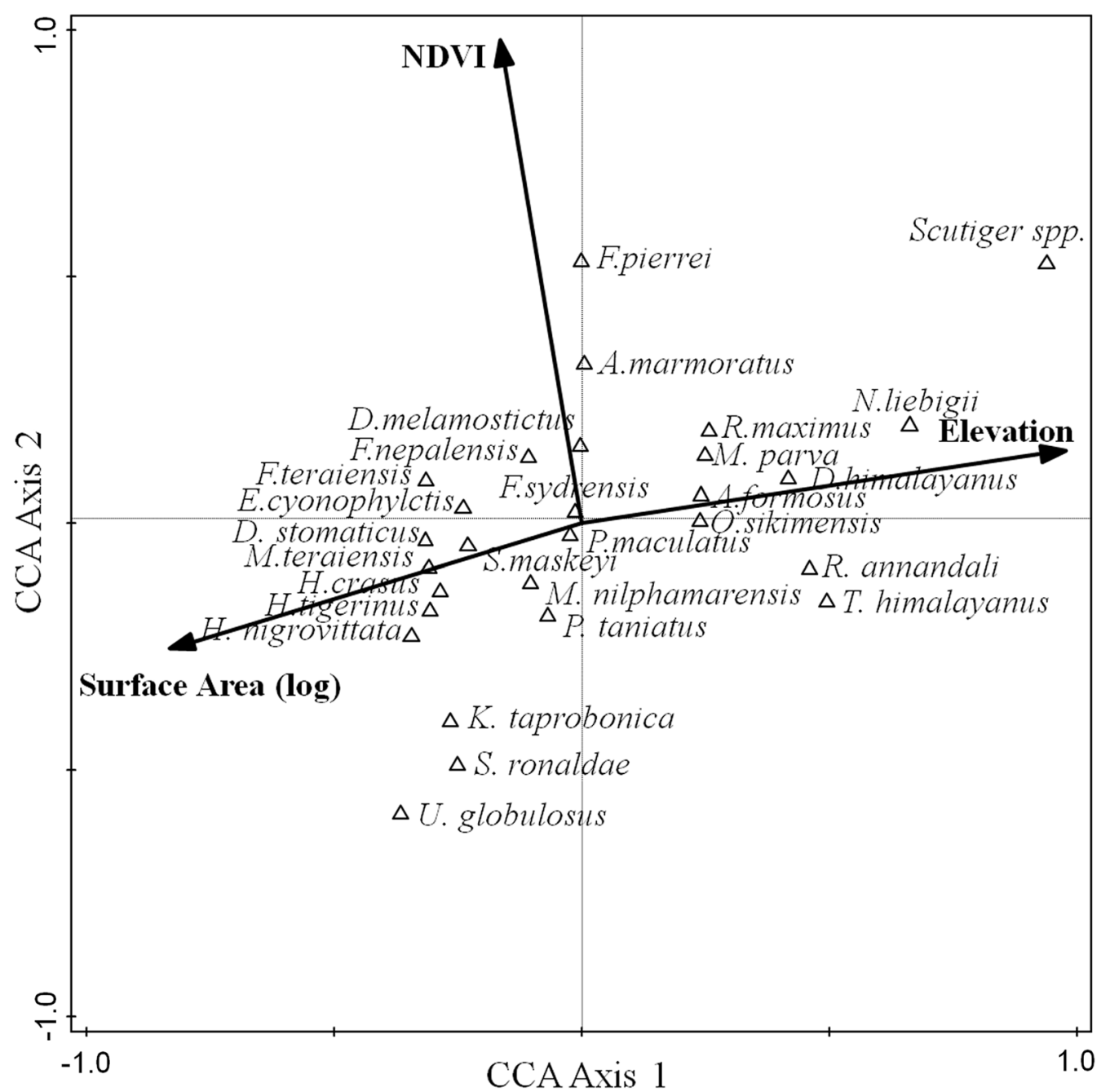

Fig. 6 Canonical correspondence analysis (CCA) showing the relationships between environmental variables and amphibian species. Only significant variables were presented with bold lines. The length of an environmental vector indicates the degree of correlation

\section{Additional files}

Additional file 1: Table S1. Available studies on vertebrate fauna along elevation gradient in the Himalayas and its neighboring countries. Table S2. Summary of variance inflation factor.

Additional file 2: Table S3. Amphibian species with total number of individuals observed in eastern Nepal Himalaya. Numbers in parenthesis refer to total percentage contribution of each species to the total sample. Figure S1. Pattern of amphibian species richness observed in eastern Nepal Himalaya along elevation gradients (black filled circles), with the open circles and triangles representing the 95\% upper and lower prediction values, respectively. Figure S2. Pattern of amphibian species richness observed in eastern Himalaya (black filled circles), with the 95\% upper (open circles) and lower (open triangles) prediction curves generated from Mid-Domain null analysis in RangeModel 5.0. Figure S3. Estimation of elevational distribution ranges of amphibian species along elevation gradients in eastern Nepal Himalaya.

\section{Authors' contributions}

JK conceived and designed the experiment, collected and analyzed the data, wrote the first draft of the manuscript. TZ wrote parts of the background and improved other parts. YC, BW, FX and DC commented on the manuscript. JJ conceived and designed the experiment, led the project and commented on the manuscript. All authors read and approved the final manuscript.

\section{Author details}

${ }^{1}$ CAS Key Laboratory of Mountain Ecological Restoration and Bioresource Utilization \& Ecological Restoration and Biodiversity Conservation Key Laboratory of Sichuan Province, Chengdu Institute of Biology, Chinese Academy of Sciences, Chengdu 610041, China. ${ }^{2}$ University of Chinese Academy of Sciences, Beijing 100049, China. ${ }^{3}$ Department of Integrative Biology, University of Texas, Austin, USA.

\section{Acknowledgements}

We are thankful to Subarna Ghimire, Purnman Shrestha, Bibas Shrestha, Bijaya Paudel, Suman Acharya and Anish Timsina for their assistance during fieldwork. We also thank two anonymous reviewers for their constructive comments that greatly improve the manuscript. We are grateful to Department of 
National Park and Wildlife Conservation (DNPWC) and Department of Forest, Government of Nepal for providing necessary research permit for conducting the research. Sincere thanks to Man Bahadur Rokaya, for the constructive suggestions in the manuscript.

\section{Competing interests}

The authors declare that they have no competing interests.

\section{Availability of data and materials}

The datasets on species richness and composition of amphibian in the eastern Himalaya and other explanatory variables used and analyzed during the current study are available from the corresponding author on reasonable request.

\section{Consent for publication}

Not applicable.

\section{Ethics approval and consent to participate}

All amphibians handling and processing were in accordance with the guidelines of the Department of National Park and Wild life Conservation, Nepal.

\section{Funding}

This work was supported by the National Key Research and Development Program of China (2017YFC0505202), the National Natural Science Foundation of China (31471964 to JJP, and 31700353 to TZ), the West Light Foundation of Chinese Academy of Sciences (2016XBZG_XBQNXZ_B_007), China Biodiversity Observation Networks (Sino BON) and the Second Comprehensive Science Investigation of Qinghai-Tibet Plateau (QTP) (II08-T05-2017-04/06). In addition, TZ was supported by China Scholarship Council (CSC), YC was supported by the Hundred Talents Program of CAS and JRK was supported by the CAS-TWAS President Fellowship and Chinese Academy of Sciences President's International Fellowship Initiative (2018PB0016).

\section{Publisher's Note}

Springer Nature remains neutral with regard to jurisdictional claims in published maps and institutional affiliations.

Received: 31 July 2018 Accepted: 16 April 2019

Published online: 02 May 2019

\section{References}

1. Körner C. The use of 'altitude' in ecological research. Trends Ecol Evol. 2007:22:569-74.

2. Sanders NJ, Rahbek C. The patterns and causes of elevational diversity gradients. Ecography. 2012;35:1-3.

3. McCain CM. Global analysis of bird elevational diversity. Glob Ecol Biogeogr. 2009;18:346-60.

4. Pyron RA. Temperate extinction in squamate reptiles and the roots of latitudinal diversity gradients. Glob Ecol Biogeogr. 2014;23:1126-34.

5. Rahbek $C$. The relationship among area, elevation, and regional species richness in neotropical birds. Am Nat. 1997;149:875-902.

6. Sanders NJ, Moss J, Wagner D. Patterns of ant species richness along elevational gradients in an arid ecosystem. Glob Ecol Biogeogr. 2003;12:93-102.

7. Whittaker RJ. Meta-analyses and mega-mistakes: calling time on metaanalysis of the species richness-productivity relationship. Ecology. 2010;91:2522-33.

8. Stein A, Gerstner K, Kreft H. Environmental heterogeneity as a universal driver of species richness across taxa, biomes and spatial scales. Ecol Lett. 2014;17:866-80.

9. Cruz-Elizalde R, Ramírez-Bautista A, Hernández-Ibarra X, Wilson LD. Species diversity of amphibians from arid and semiarid environments of the Real de Guadalcázar State Reserve, San Luis Potosí, Mexico. Nat Areas J. 2016;36:302-9.

10. Hernadez-Salinas U, Ramirez-Bautista A. Diversity of amphibian communities in four vegetation types of Hidalgo State, Mexico. Open Conserv Biol J. 2012;6:1-11.

11. Luja VH, López JA, Cruz-Elizalde R, Ramírez-Bautista A. Herpetofauna inside and outside from a natural protected area: the case of Reserva
Estatal de la Biósfera Sierra San Juan, Nayarit, Mexico. Nat Conserv. 2017;21:15-38.

12. Badillo-Saldaña LM, Ramírez-Bautista A, Wilson LD. Effects of establishment of grazing areas on diversity of amphibian communities in tropical evergreen forests and mountain cloud forests of the Sierra Madre Oriental. Rev Mex Biodivers. 2016;87:133-9.

13. Berriozabal-Islas C, Ramírez-Bautista A, Cruz-Elizalde R, Hernández-Salinas U. Modification of landscape as promoter of change in structure and taxonomic diversity of reptile's communities: an example in tropical landscape in the central region of Mexico. Nat Conserv. 2018;28:33-49.

14. Cooper N, Bielby J, Thomas GH, Purvis A. Macroecology and extinction risk correlates of frogs. Glob Ecol Biogeogr. 2008;17:211-21.

15. Whitton FJS, Purvis A, Orme CDL, Olalla-Tárraga MÁ. Understanding global patterns in amphibian geographic range size: does Rapoport rule? Glob Ecol Biogeogr. 2012;21:179-90.

16. O'Grady JJ, Brook BW, Reed DH, Ballou JD, Tonkyn DW, Frankham R. Realistic levels of inbreeding depression strongly affect extinction risk in wild populations. Biol Conserv. 2006;133:42-51.

17. Colwell RK, Lees DC. The mid-domain effect: geometric constraints on the geography of species richness. Trends Ecol Evol. 2000;15:70-6.

18. Stevens GC. The elevational gradient in altitudinal range: an extension of Rapoport's latitudinal rule to altitude. Am Nat. 1992;140:893-911.

19. Emmerson MC, Raffaelli D. Predator-prey body size, interaction strength and the stability of a real food web. J Anim Ecol. 2004;73:399-409

20. Colwell R, Hurt G. Nonbiological gradients in species richness and a spurious Rapoport effect. Am Nat. 1994;144:570-95.

21. Acharya KP, Vetaas OR, Birks HJB. Orchid species richness along Himalayan elevational gradients. J Biogeogr. 2011;38:1821-33.

22. McCain CM. The mid-domain effect applied to elevational gradients: species richness of small mammals in Costa Rica. J Biogeogr 2004;31:19-31.

23. Fu C, Wu J, Wang $X$, Lei $G$, Chen J. Patterns of diversity, altitudinal range and body size among freshwater fishes in the Yangtze River basin, China. Glob Ecol Biogeogr. 2004;13:543-52.

24. Wiens JJ, Parra-Olea G, Garcia-Paris M, Wake DB. Phylogenetic history underlies elevational biodiversity patterns in tropical salamanders. Proc $R$ Soc B Biol Sci. 2007:274:919-28.

25. Colwell RK, Rahbek C, Gotelli NJ. The mid-domain effect and species richness patterns: what have we learned so far? Am Nat. 2004;163:E1-23.

26. Gouveia SF, Correia I. Geographical clines of body size in terrestrial amphibians: water conservation hypothesis revisited. J Biogeogr. 2016;43:2075-84

27. Gaeta JW, Ahrenstorff TD, Diana JS, Fetzer WW, Jones TS, Lawson ZJ, et al. Go big or... don't? A field-based diet evaluation of freshwater piscivore and prey fish size relationships. PloS ONE. 2018;13:e0194092.

28. Blueweiss L, Fox H, Kudzma V, Nakashima D, Peters R, Sams S. Relationships between body size and some life history parameters. Oecologia. 1978;37:257-72.

29. Woodward G, Hildrew AG. Body size determinants of niche overlap and intraguild predation within a complex food web. J Anim Ecol. 2002;71:1063-74.

30. Meiri S, Dayan T. On the validity of Bergmann's rule. J Biogeogr. 2003;30(3):331-51.

31. Belk Mark C, Houston Derek D. Bergmann's rule in ectotherms: a test using freshwater fishes. Am Nat. 2002;160(6):803-8.

32. Pincheira-Donoso D, Hodgson DJ, Tregenza T. The evolution of body size under environmental gradients in ectotherms: why should Bergmann's rule apply to lizards? BMC Evol Biol. 2008;8(1):68.

33. Adams DC, Church JO. Amphibiabs do not follow Bergmann's rule. Evolution. 2008;62(2):413-20.

34. Olalla-Tárraga MÁ, Rodríguez MÁ. Energy and interspecific body size patterns of amphibian faunas in Europe and North America: anurans follow Bergmann's rule, urodeles its converse. Glob Ecol Biogeogr. 2007;16:606-17.

35. Gillespie GR, Howard S, Stroud JT, UI-Hassanah A, Campling M, Lardner B, et al. Responses of tropical forest herpetofauna to moderate anthropogenic disturbance and effects of natural habitat variation in Sulawesi, Indonesia. Biol Conserv. 2015;192:161-73.

36. Hu J, Xie F, Li C, Jiang J. Elevational patterns of species richness, range and body size for spiny frogs. PLoS ONE. 2011;6:e19817. 
37. Fu C, Hua X, Li J, Chang Z, Pu Z, Chen J. Elevational patterns of frog species richness and endemic richness in the Hengduan Mountains, China: geometric constraints, area and climate effects. Ecography. 2006;29:919-27.

38. Vetaas OR. Comparing species temperature response curves: population density versus second-hand data. JVeg Sci. 2000;11:659-66.

39. Bhattarai $K R$, Vetaas $O R$, Grytnes JA. Fern species richness along a central Himalayan elevational gradient, Nepal. J Biogeogr. 2004;31:389-400.

40. Carpenter $\mathrm{C}$. The environmental control of plant species density on a Himalayan elevation gradient. J Biogeogr. 2005;32:999-1018.

41. Chaudhary RP. Biodiversity in Nepal: status and conservation. Saharanpur: S. Devi and Tecpress Books; 1998.

42. Keller A, Rödel MO, Linsenmair KE, Grafe TU. The importance of environmental heterogeneity for species diversity and assemblage structure in Bornean stream frogs. J Anim Ecol. 2009;78(2):305-14.

43. Khatiwada JR, Haugaasen T. Anuran species richness and abundance along an elevational gradient in Chitwan, Nepal. Zool Ecol. 2015;25:110-9.

44. Khatiwada JR, Ghimire S, Paudel Khatiwada S, Paudel B, Bischof R, Jiang $J P$, et al. Frogs as potential biological control agents in the rice fields of Chitwan, Nepal. Agric Ecosyst Environ. 2016;230:307-14.

45. Khatiwada JR, Shu GC, Wang SH, Thapa A, Wang B, Jiang J. A new species of the genus Microhyla (Anura: Microhylidae) from Eastern Nepal. Zootaxa. 2017:4254(2):221-39.

46. Schleich HH, Kästle W. Amphibians and reptiles of Nepal: biology, systematics, field guide. Ruggell: ARG. Ganther Verlag KG; Koenistein, Germany; 2002. p. 1201

47. Shah KB, Tiwari S. Herpetofauna of Nepal: a conservation companion. Kathmandu: IUCN the World Conservation Union; 2004. p. 237.

48. Frost DR. Amphibian species of the World: an online reference. Version 6.0. New York: American Museum of Natural History; 2018. http://resea rch.amnh.org/herpetology/amphibia/index.html. Accessed 20 Aug 2018.

49. Lemmon PE. Spherical densiometer for estimating forest overstory density. Forest Sci. 1957;2:314-20.

50. Zhang $S B$, Chen WY, Huang JL, Bi YF, Yang XF. Orchid species richness along elevational and environmental gradients in Yunnan, China. PLoS ONE. 2015;10:e0142621.

51. Gotelli N, Entsminger G. EcoSim: null models software for ecology. Version 7.0. Jericho: Intelligence Inc. \& Kesey-Bear; 2011.

52. Heaney LR. Small mammal diversity along elevational gradients in the Philippines: an assessment of patterns and hypotheses. Glob Ecol Biogeogr. 2001;10:15-39.

53. Colwell RK. RangeModel: tools for exploring and assessing geometric constraints on species richness (the mid-domain effect) along transects. Ecography. 2008;31:4-7.

54. Cardelús CL, Colwell RK, Watkins JE. Vascular epiphyte distribution patterns: explaining the mid-elevation richness peak. J Ecol. 2006;94:144-56.

55. Wu Y, Yang Q, Wen Z, Xia L, Zhang Q, Zhou H. What drives the species richness patterns of non-volant small mammals along a subtropical elevational gradient? Ecography. 2013;36:185-96

56. Moreno RA, Rivadeneira MM, Hernández CE, Sampértegui S, Rozbaczylo N. Do Rapoport's rule, the mid-domain effect or the source-sink hypotheses predict bathymetric patterns of polychaete richness on the Pacific coast of South America? Glob Ecol Biogeogr. 2008;17:415-23.

57. Montgomery DC, Peck EA, Vining GG. Introduction to linear regression analysis. 5th ed. New Jersey: Wiley; 2012.

58. Burnham KP, Anderson DR. Model selection and multimodel inference: a practical information-theoretic approach. Berlin: Springer; 2002.

59. Venables W, Ripley B. Statistics and computing with S. 4th ed. New York: Springer; 2002

60. Chevan A, Sutherland M. Hierarchical partitioning. Am Stat. 1991;45:90-6.

61. Mac Nally R. Multiple regression and inference in ecology and conservation biology: further comments on identifying important predictor variables. Biodivers Conserv. 2002;11:1397-401.
62. Walsh C, Mac Nally R. hier.part: hierarchical partitioning. R package version 1.0-3. 2013. http://CRAN.R-project.org/package=hier.part. Accessed 15 Aug 2018.

63. Ter Braak CJF, Šmilauer P. CANOCO reference manual and CanoDraw for Windows user's guide: software for canonical community ordination (version 4.5). Wageningen: Biometris, Plant Research International; 2002.

64. Zancolli G, Steffan-Dewenter I, Rödel MO. Amphibian diversity on the roof of Africa: unveiling the effects of habitat degradation, altitude and biogeography. Divers Distrib. 2014;20:297-308.

65. Fauth JE, Crother BI, Slowinski JB. Elevational patterns of species richness, evenness, and abundance of the Costa Rican leaf-litter herpetofauna. Biotropica. 1989;21:178-85.

66. Chettri B, Bhupathy S, Acharya BK. Distribution pattern of reptiles along an eastern Himalayan elevation gradient, India. Acta Oecol. 2010;36:16-22.

67. Kluge J, Kessler M, Dunn RR. What drives elevational patterns of diversity? A test of geometric constraints, climate and species pool effects for pteridophytes on an elevational gradient in Costa Rica. Glob Ecol Biogeogr. 2006;15:358-71.

68. Bhattarai KR, Vetaas OR. Variation in plant species richness of different life forms along a subtropical elevation gradient in the Himalayas, east Nepal. Glob Ecol Biogeogr. 2003;12:327-40.

69. Funk WC, Caminer M, Ron SR. High levels of cryptic species diversity uncovered in Amazonian frogs. Proc R Soc Lond B Biol Sci. 2012;279:1806-14.

70. Marshall JL, Camp CD. Environmental correlates of species and genetic richness in lungless salamanders (family plethodontidae). Acta Oecol. 2006;29:33-44.

71. Kozak KH, Wiens JJ. Niche conservatism drives elevational diversity patterns in Appalachian salamanders. Am Nat. 2010;176:40-54.

72. Meza-Joya FL, Torres M. Spatial diversity patterns of Pristimantis frogs in the Tropical Andes. Ecol Evol. 2016;6:1901-13.

73. Ashton KG. Patterns of within species body size variation of birds: strong evidence for Bergmann's rule. Glob Ecol Biogeogr. 2002;11:505-23.

74. Blackburn TM, Hawkins BA. Bergmann's rule and the mammal fauna of northern North America. Ecography. 2004;27:715-24.

75. Rypel AL. The cold-water connection: Bergmann's Rule in North American freshwater fishes. Am Nat. 2014;183:147-56.

76. Adams DC, Church JO. Amphibians do not follow Bergmann's rule. Evolution. 2008;62:413-20.

77. Ashton KG. Do amphibians follow Bergmann's rule? Can J Zool. 2002;80:708-16.

78. Laugen AT, Laurila A, Jönsson Kl, Söderman F, Merilä J. Do common frogs (Rana temporaria) follow Bergmann's rule? Evol Ecol Res. 2005;7:717-31.

79. Preston FW. The canonical distribution of commonness and rarity: part I. Ecology. 1962;43:185-215.

80. Blaustein AR, Walls SC, Bancroft BA, Lawler JJ, Searle CL, Gervasi SS. Direct and indirect effects of climate change on amphibian populations. Diversity. 2010;2:281-313.

81. Hawkins BA, Field R, Cornell HV, Currie DJ, Guégan J-F, Kaufman DM, et al. Energy, water, and broad-scale geographic patterns of species richness. Ecology. 2003;84:3105-17.

82. O'Brien EM. Climatic gradients in woody plant species richness: towards an explanation based on an analysis of southern Africa's woody flora. J Biogeogr. 1993;20:181-98.

83. Gillman LN, Wright SD, Cusens J, McBride PD, Malhi Y, Whittaker RJ. Latitude, productivity and species richness. Glob Ecol Biogeogr. 2015:24:107-17.

84. Mittelbach GG, Steiner CF, Scheiner SM, Gross KL, Reynolds HL, Waide $\mathrm{RB}$, Willig MR, Dodson SI, Gough L. What is the observed relationship between species richness and productivity? Ecology. 2001;82:2381-96. 